\title{
CAMINAR CON LOS NIÑOS TRABAJADORES DE LA CALLE
}

\section{WALK WITH WORKING CHILDREN OF THE STREET}

\section{AUTORA}

\section{Hildegar González Luis}

Profesora de Comunicación al Desarrollo; Comunicación Institucional; Teoría y Técnica de las Relaciones Públicas en Facultad de Comunicación de Universidad de Navarra (España) betelu13@yahoo.es

\section{RESUMEN}

El contraste que hay en Panamá entre unas zonas y otras es notablemente alto. 0 bien hay una riqueza extrema, o son extremadamente pobres. Casa Esperanza intenta erradicar el trabajo infantil que esta pobreza genera en niños desde 2 a 17 años mediante la confianza de los monitores que consiguen penetrar en su entorno (sobre todo con su familia) y, finalmente, les escolarizan, les dotan de formación profesional, les ayudan a conseguir trabajos dignos y, posteriormente, les hacen un seguimiento. Así, pretenden conseguir que las tasas de trabajo infantil disminuyan hasta desaparecer.

\section{PALABRAS CLAVE}

Pobreza - Panamá - Trabajo infantil - Casa Esperanza 


\section{ABSTRACT}

The contrast in Panama in some areas and others is remarkably high. Either there is an extreme wealth, or are extremely poor. Casa Esperanza attempts to eradicate child labor that creates poverty in children from 2 to 17 years through confidence monitor that can penetrate the environment (especially family) and finally they start school, equip them vocational training, help them to get jobs worthy and then make them follow up. So, try to get child labor rates decrease and disappear.

\section{KEY WORDS}

Poverty - Panama - Child labor - Casa Esperanza

\section{ÍNDICE}

1. Algunos datos que corroboran esta idea.

2. Horas que trabajan y dinero que reciben.

3. Edades.

4. Zonas de trabajo.

5. Procedencia de los niños.

6. ¿A qué se dedican los niños?

7. Y, ante este panorama, ¿qué? Una de las soluciones en marcha.

8. Los programas que están llevando a cabo.

9. Causas para buscar el sustento en las calles.

10. La metodología de Casa Esperanza.

11. Los pilares sobre los que se asienta su metodología.

12. El personal de Casa Esperanza.

13. Los recursos económicos.

14. Objetivos principales de Casa Esperanza para niños y adolescentes.

14. Objetivos principales de Casa Esperanza para niños y adolescentes.

15. Para acabar.

16. Por si alguien pregunta 
A cualquier persona que llega a Panamá y contempla en silencio todo lo que le rodea, le resulta casi inevitable caminar por el paseo Balboa, mirar a ambos lados de la bahía y no pronunciar una palabra: contraste.

A la izquierda, el Panamá colonial, las casas de poca altura, las callejuelas estrechas, los niños por las calles. A la izquierda, el Panamá nuevo, los grandes edificios de más 40 plantas, las avenidas escoltadas por centros comerciales y bancos, los coches, los atascos y las prisas. Dos realidades que son esencia de un mismo lugar: Panamá, la ciudad de los contrastes.

El contraste también se da en el reparto de los bienes. En un país en el que el 75\% de la riqueza se concentra en el $15 \%$ de la población, los niños, sin ninguna duda, son los más desfavorecidos y los que sienten con mayor crudeza la mala distribución.

\section{Algunos datos que corroboran esta idea.}

Un estudio realizado por Fondo de las Naciones Unidas para la Infancia (UNICEF) manifiesta que, un $30 \%$ de las familias centroamericanas que viven en extrema pobreza, obtienen ingresos para su supervivencia gracias al trabajo que realizan los niños.

A pesar de que Panamá es un país en vías de desarrollo, que registra tasas de crecimiento del $3.2 \%$ en su (PIB), y está realizando un esfuerzo considerable para reducir la pobreza y el desempleo, no se libra de un problema que afecta a 250 millones de niños en todo el mundo: el trabajo infantil.

Dentro del área metropolitana de Panamá, hay 32600 hogares catalogados de extrema pobreza. Esto supone que el $14 \%$ de las familias de la ciudad no tienen los recursos mínimos para sobrevivir. Los datos revelan que 28.400 niños subsisten en 
estas condiciones. Son presas fáciles para caer en lo que, eufemísticamente se ha dado en llamar, economía informal.

\section{Horas que trabajan y dinero que reciben.}

El informe anual 1998 de Casa Esperanza, institución no gubernamental que desde 1991 orienta sus esfuerzos hacia la solución del problema del trabajo infantil en Panamá, muestra que, la mayoría de los niños laboran una media de 10 horas diarias. El aporte que obtienen oscila entre los 10 y los 20 dólares al día (entre unas1500-2000pts). Uno de los mayores problemas a los que se enfrenta Casa Esperanza es al de que, en algunas ocasiones, sacar a estos niños del trabajo en las calles supone que sus familias no dispongan de ningún ingreso para alimentarse. Son los casos más graves, pero existen. Por eso, cada niño debe ser estudiado de modo individual para buscar la solución más apropiada.

\section{Edades.}

No hay estadísticas con datos concretos sobre todos los niños que trabajan de modo informal en las calles panameñas. Sin embargo, el informe de Casa Esperanza sobre las criaturas que ella atiende, puede aportar cifras concretas que ayudan a situar el problema. El 16\% de los niños que trabajan tienen entre 2 y 5 años; el $22 \%$ de ellos entre 6 y 8; el $29 \%$ entre 9 y 11 años; el $24 \%$ entre 12 y 14; el 9\% entre los 15 y los 17. Es significativo saber que más de la mitad, el $53 \%$ de estos niños que trabajan en la calle, oscila en edades comprendidas entre los 9 y los 14 años.

\section{Zonas de trabajo.}

En la capital, las zonas más frecuentadas por los chiquillos y adolescentes para ganarse sus balboas son: Mercado de Abastos con un 32\% del total; Calidonia donde trabajan un $24 \%$ de ellos y Avenida Central con un $23 \%$. Otras calles y zonas como 
vía España, vía Argentina, La Transísmica, el mercado público o Tumba muerto también se catalogan como zonas de trabajo, aunque con porcentajes menores. Estos datos apenas han variado de 1997 a 1998. La única calle que ha sufrido un aumento considerable de niños trabajando, (10\%), ha sido la Avenida Central. A quienes conozcan Panamá y hayan caminado por sus calles creo que no les resultará difícil recordar imágenes de niños trabajando.

\section{Procedencia de los niños.}

Casi la mitad de los muchachos que la institución ha contactado recorriendo las calles proceden de la zona de Curundú (46\%). El 23\% vienen de San Miguelito y el 10\% de Chorrillo.

\section{6. ¿A qué dedican los niños?}

Los ingresos que generan los chiquillos en las calles proceden de varias actividades. La mayoría, el $40 \%$, trabaja en la venta de todo tipo de productos: bolsas, dulces, toallas, fruta... El $24 \%$ de ellos se dedican al sector servicios. Ellos son los que limpian los zapatos, los que lavan coches, los que portan las bolsas en los supermercados... El 7\% de ellos se dedican a la mendicidad. Los muchachos/as que se dedican en las calles a cualquier tipo de estos trabajos, se enfrentan a la inseguridad, los embarazos precoces, las enfermedades y la desnutrición. Este último problema es uno de los más urgentes cuando se actúa contra la explotación infantil.

\section{7. $Y$, ante este panorama, ¿qué? Una de las soluciones en marcha.}

Hay personas e instituciones que no se quedan inactivas o calladas frente a las pésimas condiciones en las que viven muchos chiquillos panameños. Actúan, 
trabajan por un presente más digno que conlleve un futuro más justo para estos muchachos.

Casa Esperanza, una de las principales instituciones no gubernamentales panameñas que trabaja en este campo, nació en 1991.

"Durante la década de los 80 había estado actuando en Panamá la organización Alianza que trabajaba con niños de la calle. De la noche a la mañana decidieron marcharse. Todo lo que había comenzado quedó en el aire. Eso no podía acabar así. Cinco educadores y yo empezamos a trabajar y a preparar poco a poco lo que luego sería Casa Esperanza", explica Roxana Méndez de Arosemena, directora de esta institución.

\section{Los programas que están llevando a cabo.}

El principal objetivo de esta institución es ofrecer a niños y adolescentes en las calles su justa oportunidad para llegar a ser ciudadanos plenos. Los niños de la calle son los que realizan actividades de tipo informal, incluso semi-ilegales en áreas públicas. Como ya he dicho, trabajan una media de 10 horas y obtienen un promedio de 10 a 20 dólares diarios. Es una injusticia que no debería dejarnos inmóviles.

Desde 1991, el número de programas de esta organización ha aumentado. En estos momentos, se llevan a cabo seis proyectos: tres comunitarios en Curundú, Samaría (San Miguelito) y La Playita (Colón); dos casas que trabajan con los niños de la calle en Colón y Panamá; y una granja agropecuaria en el área de Cermeño. Este último proyecto procura cualificar a 15 chicos cada año para que puedan enfrentarse al mundo laboral en ese campo. 


\section{Causas para buscar el sustento en las calles.}

La disolución de la familia; la extrema pobreza; las insuficientes e inadecuadas escuelas; la estructura económica del medio, y la explotación de los adultos, son, entre otras, las causas que llevan a estos niños a buscar su sustento en la calle. "A medida que se conoce mejor la situación de la familia uno se da cuenta de que, en la mayoría de los casos, no explotan al niño, sino que ese chiquillo forma parte de la dinámica familiar de supervivencia. Para complementar el trabajo que hacemos con los niños, hemos iniciado programas con las madres", comenta Roxana. A pesar de que las situaciones de explotación familiar son mínimas, también existen.

\section{La metodología de Casa Esperanza.}

Todos sus proyectos se vertebran en el eje de lograr un desarrollo integral de los niños y jóvenes que trabajan en las calles. Para conseguir esta evolución integral, la institución emplea dos metodologías: atención a los niños que están en la calle y de prevención de los que no laboran, pero que viven en las mismas condiciones que los primeros.

La metodología se inicia con los "trabajadores de calle", nombre con el que se autodenominan los miembros de la institución que salen a las avenidas en busca de niños que laboran. El primer paso es ganarse su confianza. Si los niños asocian al educador con una autoridad policial, huyen porque les tienen miedo. Los adolescentes son los más desconfiados, sobre todo si están involucrados en temas de drogas. Según explica la directora, una de las ventajas de Casa Esperanza es que, al ser una institución que lleva años trabajando, los chiquillos hablan entre ellos y transmiten su existencia. Los propios niños que ya están dentro de los programas ayudan a los monitores a contactar con otros que son sus compañeros. 
Las técnicas que los monitores emplean varían con las edades de los muchachos. Juegos de mesa, balones, deporte y ayuda de primeros auxilios, si es necesaria, son las más comunes.

Una vez que Casa Esperanza logra que el niño se interese por sus programas, se procura conocer a las madres de los chiquillos e iniciar un trabajo con ellas. Es imprescindible trabajar con el entorno que rodea a los muchachos para determinar el mejor modo de ayudarle. Cada niño es estudiado y atendido de forma individual porque cada uno tiene unas circunstancias específicas y problemas concretos. La solución de cada uno varía. Por eso hay distintos programas que emplean dinámicas que desarrollen al niño en su totalidad.

\section{Los pilares sobre los que se asienta su metodología.}

La educación es una de las prioridades de la institución. Muchos de los niños que trabajan en la calle han desertado de la escuela. Los educadores de Casa Esperanza investigan el estado de escolaridad de los niños y, si es necesario, inician los trámites para que estos niños sean admitidos en los colegios, y dispongan de la atención y los recursos necesarios. Cada niño tiene un tutor que se encarga de seguir su proceso. Él habla con los profesores del colegio, conversa con él y con su familia y hace su ficha de seguimiento. Los niños que asisten a los programas tienen un tiempo determinado para hacer los deberes del colegio en las aulas de la institución.

La salud y la nutrición. "Si hay desnutrición, solucionar eso es prioritario. Desde 1996 hasta 1998 hemos logrado que las tasas de desnutrición de los niños con los que trabajamos se redujeran de un $33 \%$ a un $4 \%$. Siempre vamos a tener niños desnutridos, porque continuamente contactamos con nuevos chiquillos". Son palabras de la directora del centro. Casa Esperanza da una comida diaria a todos lo chiquillos que participan en sus programas. En el campo de la salud se hace un seguimiento de peso y altura de cada niño, y se lleva un control médico para 
prevenir 0 detectar enfermedades. En general, estos muchachos están acostumbrados al dolor y sólo se quejan cuando ya tienen algo muy grave. Además del seguimiento médico, se le procura enseñar los síntomas de las enfermedades y los lugares donde deben acudir para ser atendidos.

En la mayoría de los casos de adolescentes, se procura sustituir el trabajo en la calle por una formación profesional que les permita ubicarse en empleos dignos y productivos como talleres de cerámica y otros materiales.

La orientación y la educación familiar. En estos campos se trabaja tanto con las madres como con los muchachos. Se busca fortalecer los lazos familiares, mejorar la autoestima, y orientar la planificación familiar.

Se llevan a cabo deportes y juegos recreativos para liberar la agresividad, potenciar el trabajo en equipo, y las relaciones sociales. Se intenta que los niños desarrollen sus capacidades artísticas y aprendan a convivir regidos con unos valores.

\section{El personal de Casa Esperanza.}

El equipo de esta institución está constituido por unas 43 personas que comienzan cobrando una media de 300 dólares mensuales. Trabajan 8 horas de lunes a sábado. La organización ha procurado que su personal esté formado por profesionales estables, porque la experiencia les ha demostrado que el trabajo voluntario eventual no es constante. Supone un gran esfuerzo preparar a un buen educador y si estos no son fijos los que salen perjudicados son los niños. Por eso, cuando aceptan voluntarios, son gente que hace un compromiso sólido para que su apoyo sea regular y al final se puedan incorporar en la institución. Por lo general, son jóvenes que realizan su práctica de Universidad. La directora dice que hay otro tipo de voluntariado, el de profesionales privados, sobre todo del campo de la salud, que se 
comprometen a atender a estos muchachos en sus consultas. "Es como una red de apoyo para casos de gravedad. Les estamos muy agradecidos", dice la directora.

\section{Los recursos económicos.}

Para desarrollar sus programas, Casa Esperanza cuenta con la aportación económica de varias empresas privadas, asociaciones, y "asociados" a título particular. Algunos municipios y comunidades en las que trabaja Casa Esperanza facilitan el local para que lleven a cabo sus actividades. Además se organizan rifas, sorteos y otras actividades para la obtención de recursos económicos. Las empresas y los panameños son, por lo general, solidarios. Todo aporte es bienvenido en esta organización ya que contribuye a mejorar las condiciones de vida de estos niños.

\section{Objetivos principales de Casa Esperanza para niños y adolescentes.}

A modo de resumen quiero enumerar los objetivos de Casa Esperanza:

1. Establecer las bases de una amistad y respeto entre ellos y sus familias.

2. Propiciar oportunidades de desarrollo para mejorar sus condiciones de vida.

3. Desarrollar la capacidad y motivación de sus familias para que respondan a las necesidades de sus hijos.

4. Prevenir la salida al trabajo de calle.

5. Promover y colaborar con proyectos orientados a mejorar las condiciones de vida en las comunidades de origen en coordinación con otras instituciones.

6. Disponer de una estructura adecuada que permita lograr los objetivos establecidos. 


\section{Para acabar}

A pesar de que hay instituciones que están llevando a cabo todo lo que está en su mano para solucionar el problema, el trabajo infantil en general, y en el país de Panamá en concreto, es una lacra a las que la sociedad en conjunto debería poner solución. La nueva Presidenta de la República de Panamá, Doña Mireya Moscoso, durante su discurso de toma de posesión, habló mucho sobre pobreza, sobre las dificultades de las madres solteras, de los derechos de la infancia y de ayuda a organizaciones e instituciones que actúen con los más desfavorecidos. Ahora que es la encargada de administrar los recursos económicos del país, todos esperan que cumpla sus promesas.

La necesidad de salir a la calle a trabajar es consecuencia de las condiciones infrahumanas en las que viven estos chiquitos. Hay que estudiar la magnitud total del problema y en la medida de lo posible erradicarlo. Los niños son los más indefensos. Solucionar sus problemas significa asegurar un porvenir más digno porque, ellos son el futuro del país.

\section{Por si alguien pregunta}

Si quiere colaborar con Casa Esperanza puede llamar a los teléfonos: 2327364 o 2327367, donde le informarán de los distintos tipos de aportes que puede hacer para que esta institución siga desarrollando la gran labor social que realiza. 